\title{
Frequency of retinal hemorrhage after thrombolysis with streptokinase in patients presenting with ST-elevation myocardial infarction: A single-center experience at a large tertiary care center in Lahore, Pakistan
}

\author{
Sarmad Zahoor ${ }^{1}$, H afiz M udabbar M ahboob ${ }^{1}, \mathrm{H}$ afiz M uhammad Sajid Jehangir ${ }^{2}$, Bilal M ehmood ${ }^{3}$, Aleena \\ K han ${ }^{4}$, U sama I qbal ${ }^{5}$ \\ ${ }^{1}$ Post G raduate Resident, D epartment of Internal M edicine, King Edward M edical U niversity / M ayo H ospital, L ahore, Pakistan, ${ }^{2} A s s i s t a n t$ \\ Professor, D epartment of Emergency M edicine, King Edward M edical U niversity / M ayo H ospital, Lahore, Pakistan, ${ }^{3} \mathrm{C}$ onsultant Physician, \\ D epartment of Internal M edicine, K ing E dward M edical U niversity / M ayo H ospital, L ahore, Pakistan, ${ }^{4}$ Research Assistant, Allama I qbal M edical \\ College / Jinnah H ospital, L ahore, Pakistan, ${ }^{5}$ C onsultant O phthalmologist, D H Q H ospital, G ujranwala, Pakistan. \\ Correspondence to: D r. Sarmad Zahoor, Email: drsarmadzahoor@gmail.com
}

\begin{abstract}
Background: Thrombolytic therapy with streptokinase is the mainstay of pharmacological treatment in acute myocardial infarction in Pakistan. Retinal hemorrhage is a common complication of streptokinase-induced thrombolysis and is often overlooked which can lead to permanent vision loss. T herefore, this study was carried out to determine the frequency of retinal hemorrhage after thrombolysis with streptokinase in patients presenting with ST elevation myocardial infarction (ST EMI).

Patients and methods: It was an observational, cross-sectional study conducted at the E mergency D epartment of M ayo $\mathrm{H}$ ospital Lahore from 11-08-2015 to 10-02-2016. T he patients underwent injection of streptokinase (1.5 million U) intravenously over $60 \mathrm{~min}$ and intravenous heparin $5,000 \mathrm{U}$ bolus followed by 1,000 U/hour. Then patients were followed up for 24 hours followed by the ophthalmoscopy to confirm the presence of retinal hemorrhage. The data were entered and analyzed using SPSS version 20.

Results: A total of 130 patients were included in this study. T he mean age of patients was $62 \pm 9.86$ years. The male to female ratio was 1.6:1. T he retinal hemorrhage was present in $17(13.08 \%)$ patients. About $80(61.5 \%)$ were diabetics and $96(73.8 \%)$ were hypertensive. Stratified variables like age, gender, hypertension, and diabetes were not found associated with retinal hemorrhage ( $p$-value $\geq 0.05$ ).

Conclusion: Retinal hemorrhage was found in $13.08 \%$ after streptokinase injection in patients presenting with ST EM I. Although the association was statistically insignificant but still the proportion of retinal hemorrhage was substantially high in these patients. T his higher percentage demands vigilant monitoring with the drug for timely diagnosis of this ignored complication which latter can be proved hazardous to the vision.

Keywords:

M yocardial Infarction, ST elevation, Streptokinase, T hrombolysis, R etinal hemorrhage
\end{abstract}

\section{INTRODUCTION}

M yocardial infarction (MI) is a major health concern in the modern world, an important cause of death in the whole world covering approximately $31.5 \%$ of all deaths worldwide of which $1 / 3^{\text {rd }}$ die even before reaching the hospital without medical care and $1 / 2$ die later within the hospital. ${ }^{1,2}$ The incidence of MI increases with advancing age. ${ }^{3}$

M ost ST -segment elevation myocardial infarction (ST EM I) are due to coronary artery disease and require

C onflict of interest: T he authors declared no conflict of interest exists.

Citation: Zahoor S, M ahboob M H, Jehangir HMS, M ehmood B, Khan A, Iqbal $U$. Frequency of retinal hemorrhage after thrombolysis with streptokinase in patients presenting with ST -elevation myocardial infarction: A single-center experience at a large tertiary care center in Lahore, Pakistan. J Fatima Jinnah M ed U niv. 2021; 15(2): 87-90.

D OI: https://doi.org/10.37018/BXOS4371 immediate medical attention. The main aim of treatment is to potentially save viable cardiac tissue. T he main treatment is thrombolysis and Percutaneous Coronary Intervention ( $\mathrm{PCI})$. T he best treatment for STEMI is $\mathrm{PCl}$ if done in time. ${ }^{4}$ If $\mathrm{PCl}$ facility is not available then thrombolysis within half an hour of arrival in hospital is recommended. ${ }^{5}$ Commonly used thrombolytic agents are streptokinase (SK), alteplase, reteplase, and tenecteplase. In Pakistan, SK is most commonly used for thrombolysis. Along with its required beneficial effects, it causes some serious complications that require immediate medical attention. ${ }^{6}$ Complications may include hemorrhage, allergic reaction, embolism, stroke, and reperfusion arrhythmias. ${ }^{6}$

Retinal hemorrhage is a very significant but often clinically overlooked complication of SK-induced 
thrombolysis. ${ }^{7,8}$ In retinal hemorrhage, bleeding occurs from fragile blood vessels in the posterior eye. ${ }^{9}$ Retinal hemorrhage can cause fibrosis in the submacular area, damage to rods and cones which are the light-sensitive cells in the eye leading to marked impairment in the vision, and also can cause neovascular glaucoma. ${ }^{10}$

Different studies conducted in the past have shown a variable incidence of retinal hemorrhage after SK induced thrombolysis varying from $9.1 \%$ in one study to $0.1 \%$ in another study. ${ }^{11,12} \mathrm{~N}$ o recent data is available that accurately comments on the incidence of retinal hemorrhage after SK in patients of ST EM I. T his study was carried out at M ayo hospital Lahore, to seek the incidence of retinal hemorrhage in patients who were suffering from ST EMI and going through SK-induced thrombolysis. The study will also help us to draw attention to this significant complication of SK intervention and define protocols to prevent it.

\section{PATIENTS AND METHODS}

It was an observational, cross-sectional study conducted at the $E$ mergency $D$ epartment of $M$ ayo hospital $L$ ahore from 11-08-2015 to 10-02-2016 after getting permission from the ethical review board of the institution. A sample size of 130 was calculated with an expected percentage of $9.1 \%$ after thrombolysis with SK (keeping a confidence interval of $95 \%$ and a $5 \%$ margin of error). ${ }^{11}$ Patients were enrolled through a non-probability consecutive sampling technique. Patients between 18 and 75 years with no previous history of MI, diagnosed recently with MI, treated with SK within 12 hours of diagnosis were included in the study. Any patient of MI with a previous history of M I, presenting after 12 hours of symptoms, on anticoagulant therapy, having hazy media or cataract not suitable for ophthalmoscope, having diabetic retinopathy or glaucoma was excluded. Demographic data (name, age, gender, contact) was also noted. The patients underwent injection SK, 1.5million $U$, intravenously over 60 minutes. Along with SK, a bolus of 5000 units of heparin was also given followed by 1000 units/hour continuously for the next 24 hours. Then patients were shifted to the ward and were followed up there for 24 hours for any complaint on change or decrease in vision. After 24 hours, patients underwent ophthalmoscopy for confirmation of the presence of retinal hemorrhage. O phthalmoscopy was done by a single consultant ophthalmologist with more than 5 years of experience in the field. Collected data was analyzed as mean, standard deviations for age and percentages, and frequency for gender, presence or absence of hypertension, and diabetes. Data were further stratified for age, gender, and comorbidities like diabetes and hypertension. Chi-square was used to calculate the post-stratification $p$-value and a $p$-value $\leq 0.05$ was considered as significant.

\section{RESULTS}

T his study included a total of 130 patients. T heir mean age was $62.32 \pm 9.86$ years with 45 being the minimum and 75 being the maximum age. The number of male patients was $80(61.54 \%)$ while the number of females was $50(38.40 \%)$. The male/female ratio was 1.6:1. While considering comorbidities, patients were evaluated for diabetes and hypertension based on past clinical history. O ut of 130 patients, $80(61.5 \%)$ patients were diabetic and 96 (73.8\%) were hypertensive. Retinal hemorrhage was observed in 17 (13.08\%) patients, whereas $113(86.92 \%)$ patients did not develop retinal hemorrhage. W hile studying the correlation of retinal hemorrhage after thrombolysis with clinical variables i.e. age, gender, diabetes, and hypertension, no statistically significant correlation was observed for any of the clinical variables ( $p$-value $\geq 0.05$ ). It indicates that the post thrombolysis retinal hemorrhage can occur with the same probability in patients irrespective of their age, gender, diabetic and hypertensive status. Table 1 summarizes the demographic and clinical characteristics of the patients reported with thrombolysis-induced retinal hemorrhage.

\section{DISCUSSION}

Ischemic heart disease (IHD) is considered to be the most important cause of disability worldwide and the death rate due to it is expected to be substantially high by $2030 .{ }^{12}$ Sub-classification includes NSTEMI and ST EM I. T he major cause of ST EM I is coronary artery disease., ${ }^{2,11}$ It may lead to systolic or diastolic heart failure, increased predisposition to arrhythmias, and

Table 1. The demographic and clinical characteristics of the patients reported with thrombolysis-induced retinal hemorrhage

\begin{tabular}{cccc}
\hline \multirow{2}{*}{ Characteristics } & \multicolumn{2}{c}{ Retinal hemorrhages } & \multirow{2}{*}{ p-value } \\
\cline { 2 - 3 } & $\begin{array}{c}\text { Present } \\
n(\%)\end{array}$ & $\begin{array}{c}\text { Absent } \\
n(\%)\end{array}$ & \\
\hline Age & & & 0.61 \\
\hline U pto 60 & $7(5.38)$ & $67(51.5)$ & \\
\hline Above 60 & $10(7.69)$ & $46(35.4)$ & 0.17 \\
\hline G ender & & & \\
\hline M ale & $9(6.92)$ & $71(54.6)$ & 0.5 \\
\hline Female & $8(6.15)$ & $42(32.3)$ & \\
\hline Diabetes & & & \\
\hline Present & $13(10.0)$ & $67(51.5)$ & \\
\hline Absent & $4(3.08)$ & $46(35.4)$ & \\
\hline H ypertension & & $82(63.1)$ & \\
\hline Present & $14(10.8)$ & $31(23.8)$ & \\
\hline Absent & $3(2.31)$ & & \\
\hline
\end{tabular}


other long-term complications. Coronary thrombolysis and mechanical revascularization have played a significant role in the therapeutic management of M I. It works by lysing the thrombus and enhancing reperfusion thus preserving the myocardium and its function and improving survival subsequently. ${ }^{11}$ ST E M I is an extreme emergency and mandates immediate medical intervention. Primary $\mathrm{PCl}$ is the most preferred treatment. If it cannot be offered, then thrombolysis using streptokinase, alteplase, reteplase or tenecteplase is the next best possible treatment mode to opt. $^{8}$ Other than desired therapeutic effects, the thrombolytic agents also produce clinically significant side effects and complications that require immediate medical attention. $\mathrm{H}$ emorrhage is a major complication of thrombolytic therapy. Retinal hemorrhage is a condition in which retinal blood vessels rupture resulting in bleeding in retinal tissue. It is diagnosed by examining the posterior of the eye via fundoscope or ophthal moscope. ${ }^{9} \mathrm{~T}$ his study evaluated the frequency of retinal hemorrhage after SK-induced thrombolysis in patients with STEMI. T he male to female ratio was 1:1.6 with male predominance. This is very much in accordance with already conducted studies claiming higher incidence of ST EMI in men..$^{2,13} \mathrm{O}$ ut of 130,80 $(61.5 \%)$ patients were diabetic and $96(73.8 \%)$ patients were hypertensive. This implicates an already established strong association of these comorbidities with ST EM Is. Similarly, a major fraction of participants were above 50 years of age, hence, indicating old age to be the major risk factor for developing STEMIs. ${ }^{14}$ Frequency of retinal hemorrhage after SK-induced thrombolysis in this study was $13.08 \%$ (17 out of 130 ). $\mathrm{N} 0$ recent clinical data is available to correlate the results but these results are very much in accordance with an al ready published data in 1997, that claimed the incidence of retinal hemorrhage was $9.1 \%$ after SK induced thrombolysis in patients presenting with ST EM Is. ${ }^{6}$ A case report from India mentions orbital hemorrhage post thrombolytic therapy in 55 years normotensive male patient. ${ }^{15}$ Another case report suggests post thrombolytic vitreoretinal hemorrhage in an 84-year-old patient with ischemic stroke. ${ }^{7}$ On the other hand, there are some studies published in the late 1990s that report a very decreased incidence of retinal hemorrhage $(0.1 \%)$ in patients with SK-induced thrombolysis., ${ }^{9,16} \mathrm{~T}$ his massive difference in results could be probably due to the nonexistence of advanced medical equipment and techniques to confirm the presence of retinal hemorrhage in earlier studies. Diabetic retinopathy is considered a relative contraindication while uncontrolled hypertension is an absolute contraindication to the use of thrombolytics as these co-morbidities increase the risk of post-therapy hemorrhagic complications. ${ }^{17,18} \mathrm{H}$ owever, this study did not show a significant $p$-value to establish an association between these comorbid conditions and the occurrence of retinal hemorrhage after SK use. $\mathrm{N}$ either did it prove any association of age and gender with it. $\mathrm{H}$ enceforth, retinal hemorrhage remains a major clinical concern of SK-induced thrombolysis and the patient and family must be counseled regarding its hazardous effects on the eyes which include temporary or permanent impairment of vision alongside other complications particularly in cases with already existing ocular disease $^{5,19}$ The final decision should be made by weighing the benefits against risks. Ophthalmology consultation would be of high value in this regard.

A few limitations of this study are its small sample size and unicentral nature. Further, it did not take into account the co-existing risk factors in patients experiencing retinal hemorrhage. But we strongly believe that if such studies are carried out at a larger scale with a larger sample size and are multicentre, we would be able to accurately comment on this clinical concern of SK therapy.

This is recommended to seek the incidence of retinal hemorrhage with different doses of SK as the incidence may be different with different doses of SK. Getting to know all this in the future will greatly improve our clinical practices and will decrease the incidence of retinal hemorrhage after SK in patients presenting with ST EM IS.

\section{CONCLUSION}

There is a significantly higher percentage of retinal hemorrhage after SK in patients of ST-segment elevation MI. T his complication needs to be addressed to avoid any loss of vision. Early involvement of an Ophthalmologist and regular follow-up will help to reduce ophthalmic hazards of SK.

\section{REFERENCES}

1. Benjamin EJ, Blaha M J, C hiuve SE, C ushman M, D as SR, D eo $R$, et al. H eart disease and stroke statistics-2017 U pdate: A report from the American Heart Association. Circulation. 2017;135 10): e146-e603.

2. Mechanic OJ, Grossman SA. Acute myocardial infarction. StatPearls [Internet]. 2019 D ec 27.

3. Rodgers JL, Jones J, Bolleddu SI, V anthenapalli S, Rodgers LE, Shah K, et al. Cardiovascular risks associated with gender and aging. J C ardiovasc D ev D is. 2019 Jun;6(2):19.

4. Lassen JF, Bøtker HE, T erkelsen CJ. T imely and optimal treatment of patients with STEMI. Nat Rev Cardiol. 2013;10(1):41-8. 
5. Streptokinase side effects: Common, severe, long term. D rugs.com [Internet]. July 5, 2020 [cited Mar 7, 2021]. Available fromhttps://www.drugs.com/sfx/streptokinase-sideeffects.htmlAccessed: 2021-03-07.

6. Retinal haemorrhage. W ikipedia.org [Internet]. [cited $\mathrm{M}$ ar 7,2021]; Available from: https://en.wikipedia.org/wiki/ Retinal_haemorrhage.

7. Peyman $M$, Subrayan V. Irreversible blindness following intravenous Streptokinase. JAMA Ophthalmol. 2013;131(10):1368-9.

8. Lee S, Gjerde H, Gubitz, G. Retinal and choroidal haemorrhage after tissue plasminogen activator administration. Can J N eurol Sci. 2017,44(4),461-2.

9. M ahaffey $\mathrm{KW}, \mathrm{G}$ ranger $\mathrm{CB}, \mathrm{T}$ oth $\mathrm{CA}, \mathrm{W}$ hite $\mathrm{HD}$, Stebbins $A L$, Barbash GI, et al. Diabetic retinopathy should not be a contraindication to thrombolytic therapy for acute myocardial infarction: Review of ocular hemorrhage incidence and location in the GUSTO-I Trial fn1. J Am Coll Cardiol. 1997;30(7):1606-10.

10. Kanukollu VM, Ahmad SS. Retinal Hemorrhage. StatPearls. [Internet] 2020 Aug. Available from: https://www.ncbi.nIm.nih. gov/books/ N BK 560777/

11. Berkowitz SD, G ranger CB, Pieper KS, L ee KL, G ore JM, Simoons $M$, et al. Incidence and predictors of bleeding after contemporary thrombolytic therapy for myocardial infarction. Circulation 1997;95(11):2508-16.

12. Zafari AM. M yocardial infarction. M edscape [Internet]. 2015 [cited 2021]; Available from: http://emedicine.medscape.com/ article/155919-overview\#2.
13. Kaba R, Cox D, Lewis A, Bloom P, Dubrey S. Intraocular haemorrhage after thrombolysis. The Lancet. 2005;365(9456):330.

14. M CM anus DD, G ore J, Yarzebski J, Spencer F, L essard D, Goldberg RJ. Recent trends in the incidence, treatment, and outcomes of patients with STEMI and N ST EMI. Am J M ed. 2011;124(1):40-7.

15. Guidance on the use of drugs for early thrombolysis in the treatment of acute myocardial infarction. nice.org. [Internet] 2002 [cited 2021]; Available from: https://www.nice.org.uk/ guidance/ta52.

16. Divya K, Vikrant K, Raghuram A, Yazhini T. O rbital and intracranial hemorrhage following thrombolysis: A case report. J Clino phthalmol Res. 2015;3(3):155-8.

17. Hormese $M, W$ ichter $M$. Vitreo-retinal hemorrhage after thrombolysis in a patient with acute ischemic stroke: a case report. Front $\mathrm{N}$ eurol. 2012 8;3:71.

18. Antman EM, Anbe DT, Armstrong PW, Bates ER, G reen LA $H$ and $M$, et al. ACC/AHA guidelines for the management of patients with ST-elevation myocardial infarction-executive summary: a report of the American College of Cardiology/American $\mathrm{H}$ eart Association Task Force on Practice Guidelines (W riting Committee to Revise the 1999 Guidelines for the $M$ anagement of Patients $W$ ith Acute M yocardial Infarction). J Am C oll C ardiol. 2004;44(3):671-719.

19. Kytö V, Sipilä J, Rautava P. Gender, age and risk of ST segment elevation myocardial infarction. Eur J Clin Investig. 20140 ct;44(10):902-9. 